\title{
PP15
}

\section{PRELIMINARY RESEARCH ON MATHEMATIC MODEL OF EYE'S ADAPTATION LUMINANCE}

\author{
Shuxiao Wang
}

DOI 10.25039/x46.2019.PP15

from

CIE x046:2019

\author{
Proceedings \\ of the \\ 29th CIE SESSION \\ Washington D.C., USA, June 14 - 22, 2019 \\ (DOI 10.25039/×46.2019)
}

The paper has been presented at the 29th CIE Session, Washington D.C., USA, June 14-22, 2019. It has not been peer-reviewed by CIE.

(C) CIE 2019

All rights reserved. Unless otherwise specified, no part of this publication may be reproduced or utilized in any form or by any means, electronic or mechanical, including photocopying and microfilm, without permission in writing from CIE Central Bureau at the address below. Any mention of organizations or products does not imply endorsement by the CIE.

This paper is made available open access for individual use. However, in all other cases all rights are reserved unless explicit permission is sought from and given by the CIE.

CIE Central Bureau

Babenbergerstrasse 9

A-1010 Vienna

Austria

Tel.: +4317143187

e-mail: ciecb@cie.co.at

www.cie.co.at 


\title{
PRELIMINARY RESEARCH ON MATHEMATIC MODEL OF EYE'S ADAPTATION LUMINANCE
}

\author{
Wang Shuxiao ${ }^{1,2}$ \\ ${ }^{1}$ Tianjin University, Tianjin, China, ${ }^{2}$ China Academy of Building Research, Beijing, CHINA \\ Wangshuxiao417@163.com
}

DOI 10.25039/x46.2019.PP15

\begin{abstract}
CIE recognizes the need for a comprehensive research program to develop a fundamental model of discomfort glare as its Top Priority Topics of research strategy. One drawback for current glare evaluation models is their faults to take average environment luminance as an indicator for visual adaptation, which means that luminance distribution and glare sources are not taken into account. There is no doubt that the measurement or estimation of adaptation level in natural environments is practically important.

IpRGCs act as a photon counter in the same way than a light meter in a camera, which project to the olivary pretectal nucleus (OPN) to control pupil light responses. In this research we will establish a facility to simulate different luminance distribution with a diameter $2.4 \mathrm{~m}$ LED semisphere screen, and monitor the pupil diameter with eye tracker. A preliminary model will be developed on the basis of collected data.
\end{abstract}

Keywords: Discomfort Glare, Adaptation luminance, Pupil diameter, ipRGC

\section{Introduction}

According to CIE DIS 017-2017, glare is the condition of vision in which there is discomfort or a reduction in the ability to see details or objects, caused by an unsuitable distribution or range of luminance, or by extreme luminance contrasts ${ }^{[1]}$. Glare is the sensation produced by luminance within the visual field that is sufficiently greater than the luminance to which the eyes are adapted to cause annoyance, discomfort or loss in visual performance and visibility ${ }^{[2]}$.

As a very important parameter for visual environment evaluation, glare is a hotspot and difficult topic of this field. CIE recognizes the need for a comprehensive research program to develop a fundamental model of discomfort glare as its Top Priority Topics of research strategy. Most glare assessments method can be expressed as the following formula:

$$
G=\sum_{i=1}^{n}\left(\frac{L_{s}^{e} \omega_{s}^{f}}{L_{a}^{g} f(\psi)}\right)
$$

where
$G \quad$ is the glare index expressing the subjective judgement;
$e, f, g$ are weighting exponents;
$f(\psi)$ is the function of the displacement angle;
$\psi$ is the angular displacement of the glare source from the observer's line of sight;
$L_{s}$ is the luminance of the glare source;
$\omega_{s}$ is the solid angle of the glare source;
$L_{a}$ is the adaptation luminance of the observer;
$n$ is the number of the glare sources. 
So the key factors influencing the glare perception can be:

Luminance of glare source

_ Apparent size of the glare source (solid angle)

_ Location of glare source in the visual field

- Number of glare sources

- Adaptation luminance

One of the most useful operations in our visual system is "adaptation" or "automatic gain control", to adjust the sensitivity of the system to a certain level of luminance so that all the responses are made to lie in the same limited dynamic range ${ }^{[3]}$. According to <Code for lighting> of CIBSE, visual adaptation is governed by the luminance of the various elements within the field of view, the sizes of the areas involved, and their location with respect to the lines of sight of observers. The adaptation luminance of the eye will play important role on glare evaluation ${ }^{[4]}$.

The adaptation luminance is conventionally determined by the average background luminance of the visual field. For instance, the adaptation luminance of UGR is defined as the uniform luminance of the whole surrounding, which produces the same illuminance on a vertical plane at the observer's eye, as the visual field under consideration, excluding the glare sources ${ }^{[5]}$. The adaptation luminance of VCP is defined as the average luminance of the entire field of view [2]. The adaptation luminance of GR or $\mathrm{Tl}$ is defined as the average luminance of a specified surface being observed (road surface and ect.) ${ }^{[6]}$.

In everyday lives, however, we see an object or a light in complex surrounds consisting of objects and lights of various luminance and chromaticity. We should know the adaptation level of the visual system to a complex field in order to make an accurate evaluation of glare. Hopkinson [3] pointed out that the large glare source influences the adaptation level. Wonwoo demonstrate the influence of local background luminance on glare perception ${ }^{[7]}$. Therefore, the conventional method, that uses the average luminance of the field of view as the background luminance is not suitable for the evaluation of discomfort glare. When the background contains areas of different luminance, the adapting luminance is mainly affected by the luminance of each area. But there is no research concerning the level of visual adaptation not only in experimental conditions but also in natural and complex environments.

So it is really an urging task to carry out research on visual adaptation mechanism, which make us better understand the formation mechanism, and provide us technical supporting measures to glare evaluation.

\section{Research Methodology}

\subsection{Research Apparatus}

Many authors have previously used a sphere/hemisphere with diffuse painting, like Goldmann perimeter, in the studies of discomfort glare, because it provides a uniform adaptation luminance $e^{[8,9,10,11]}$. In this research a hemisphere LED screen for producing a complex luminance distribution for subjects is established, with the following characters:

Table 1 - Characters of the hemisphere LED screen

\begin{tabular}{|l|l|l|l|}
\hline Diameter $(\mathrm{m})$ & 2.4 & Quantity of pixel & 723360 \\
\hline Colour & R/G/B & Maximum luminance $(\mathrm{cd} / \mathrm{m} 2)$ & 1000 \\
\hline AD conversion & $12 \mathrm{bit}$ & Pixel distance $(\mathrm{mm})^{*}$ & $1.875 / 3 / 4 / 5$ \\
\hline${ }^{*}$ The distribution of different pixel arrangement is shown in figure 1 \\
\hline
\end{tabular}



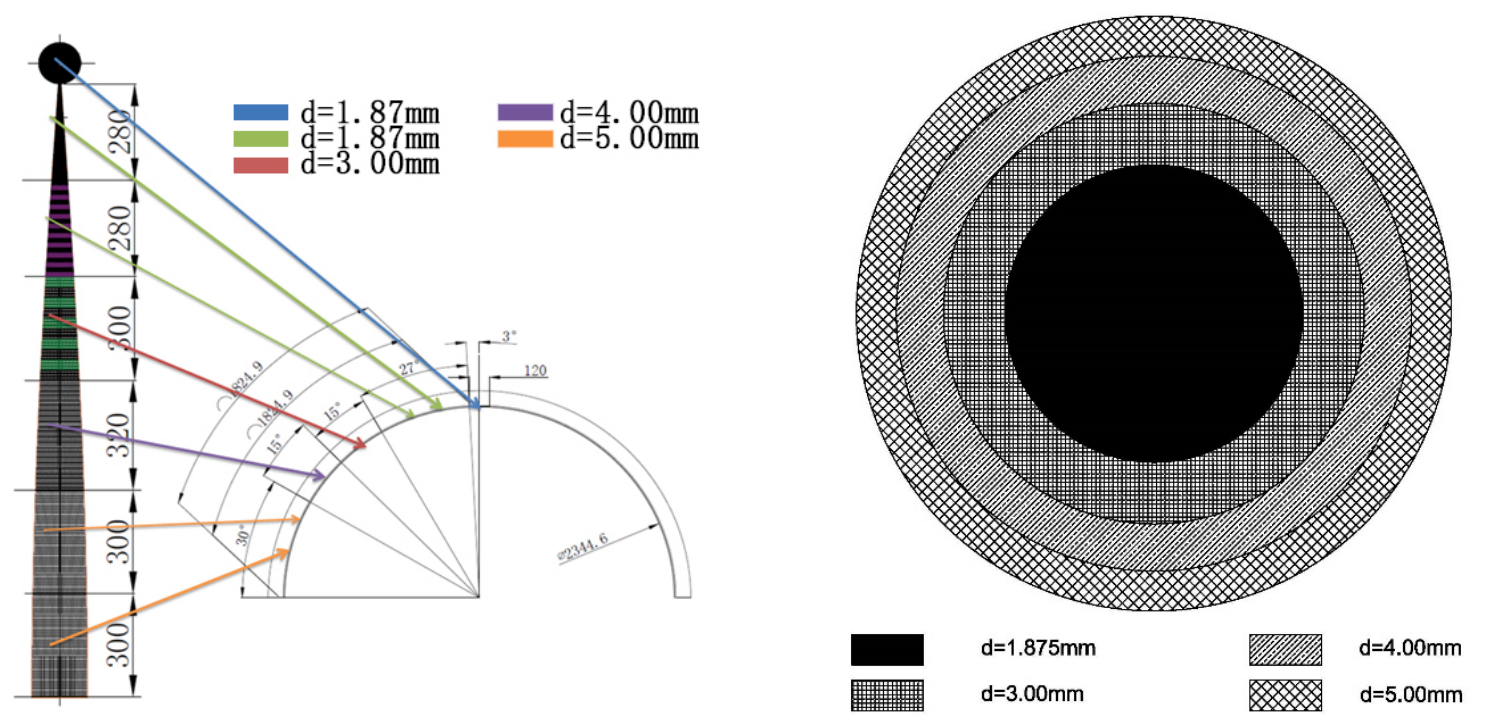

d: pixel distance

Figure 1 - The distribution of different pixel arrangement

The subject positioning station by the chinrest used to fix the subject's head position (Figure 2). The observer's eyes were located at the center of the hemisphere LED screen, so that the distance between the observer's eyes and the surface of the sphere was $1.2 \mathrm{~m}$. During the experiment the subjects had to adjust, if necessary, the height of the chair to match their eye level and the mark on the chinrest (this was checked by the experimenter). A Tobii Pro Glasses 2 eye tracker to monitor and record the pupil diameter data.

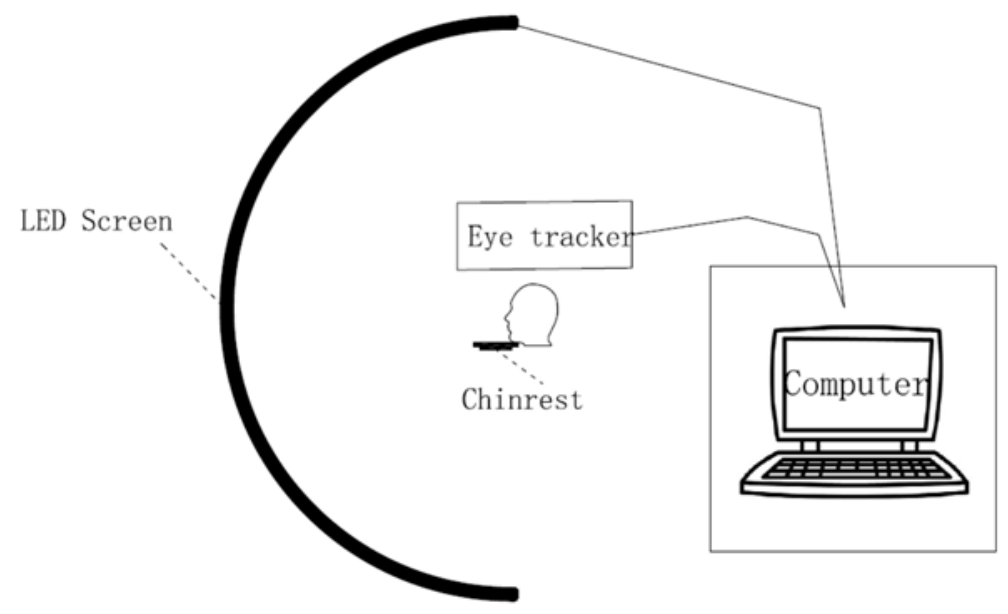

Figure 2 - Schematic of research methodology

\subsection{Indicator for eye adaptation}

Pupil size depends mainly on the adapting luminance, modulated by other factors, and pupil area decreases with increasing irradiance over a huge intensity range. According to related research, IpRGCs act as a photon counter in the same way than a light meter in a camera [12]. This unique capability, not shared by other photoreceptors, could serve as a reference for the visual system to optimize light adaptation. And IpRGCs project to the olivary pretectal nucleus (OPN) to control pupil light responses ${ }^{[13]}$. A key feature of the light reflex is its tonic nature in bright light: constriction is held steady under continuous illumination ${ }^{[14]}$. In this research, the relative pupil constriction is used as indicator for eye adaptation. 


\subsection{Scenario of research}

In the preliminary research stage, we will conduct several experiments to verify the following hypothesis:

1) There is difference on pupil constriction between different CCT scenario;

2) Same vertical illuminance on the eye may have different eye adaptation state.

\subsubsection{CCT difference verification}

The LED screen will be set in the following two CCT scenario with the uniform luminance distribution in full visual field:

Scenario 1: CCT $24200 \mathrm{~K}$, the detail information of spectrum is shown in figure 3.a;

Scenario 2: CCT $3460 \mathrm{~K}$, the detail information of spectrum is shown in figure 3.b.

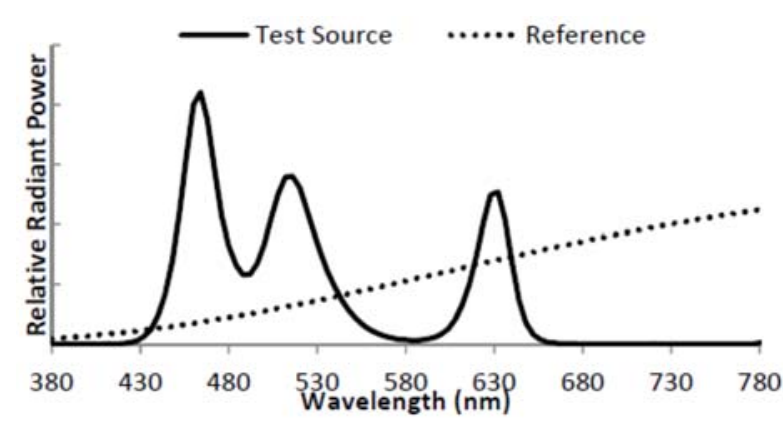

Correlated colour temperature $(K): 24200$ Distance to Blackbody Locus $\left(D_{\mathrm{uv}}\right): 0.025$

\section{a) Scenario 1}

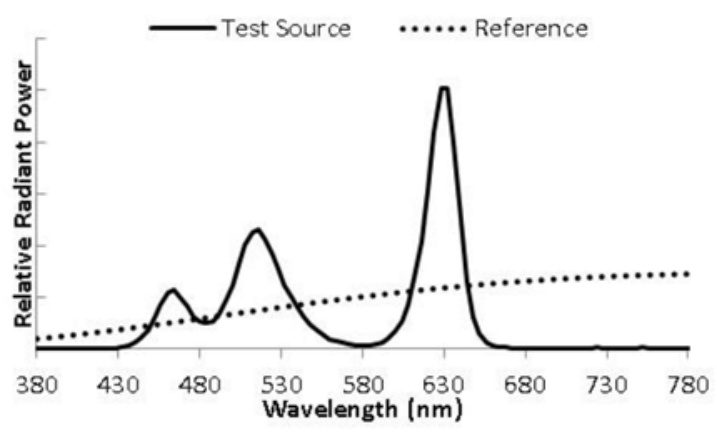

Correlated colour temperature $(\mathrm{K}): 3460$ Distance to Blackbody Locus $\left(D_{\mathrm{uv}}\right):-0.0044$

b) Scenario 2

Figure 3 - Relative spectrum distribution of two research scenario

\subsubsection{Luminance distribution}

According to UGR computation method, the vertical illuminance from the environment (excluding the glare sources) is taken as the indicator for the adaptation luminance of the eye, which means the distribution of the environment is not considered. This experiment will make a verification on this assumption, and three scenarios are used:

Scenario 3: CCT $24200 \mathrm{~K}$, full screen with a uniform luminance of $1.37 \mathrm{~cd} / \mathrm{m}^{2}$, the vertical illuminance on the participant eye is $8.61 \mathrm{x}$;

Scenario 4: CCT $24200 \mathrm{~K}$, only the center part of the Screen (diameter of this part is $120 \mathrm{~mm}$, as figure 4 shown) is on with a luminance of $1090 \mathrm{~cd} / \mathrm{m}^{2}$, the vertical illuminance on the participant eye is $8.61 \mathrm{x}$;

Scenario 5: CCT $24200 \mathrm{~K}$, only a belt of the screen (as figure 5 shown) is on with a luminance of $4.31 \mathrm{~cd} / \mathrm{m}^{2}$, the vertical illuminance on the participant eye is $8.61 \mathrm{x}$. 


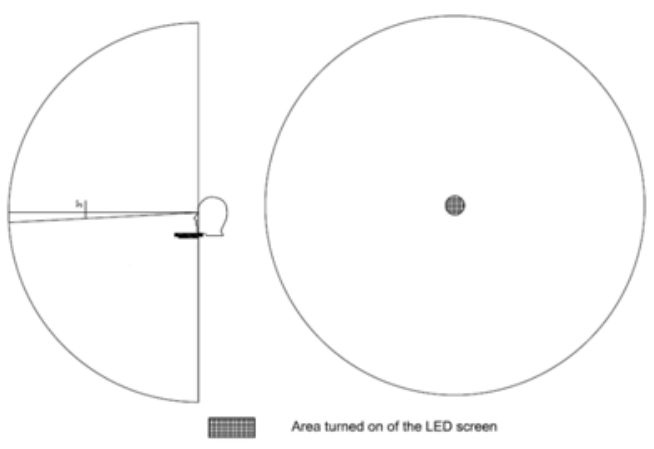

Figure 4 - Schematic of scenario 4

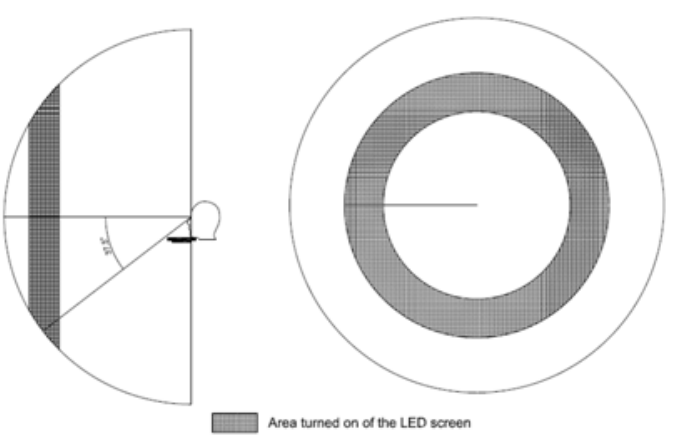

Figure 5 - Schematic of scenario 5

\section{Data Analysis}

One 37-year male participant undertaking all these experiments in the same morning session (9:00:11:00), and during each experiment scenario, there will be a ten minutes break.

\subsection{CCT difference verification}

All the experiment data difference between different scenario are statistically significant, and from these data (as figure 6 shown), we can find that:

1) The pupil diameter reduces with the increase of background luminance, but there is threshold that pupil constriction will approach to a limit. In the scenario 1 , when the luminance of LED screen is higher than $120 \mathrm{~cd} / \mathrm{m}^{2}$, the difference of pupil diameter is not so significant.

2) There is relationship between spectrum of light (here we use CCT as an indicator) and pupil constriction, and higher CCT have higher influence power. 


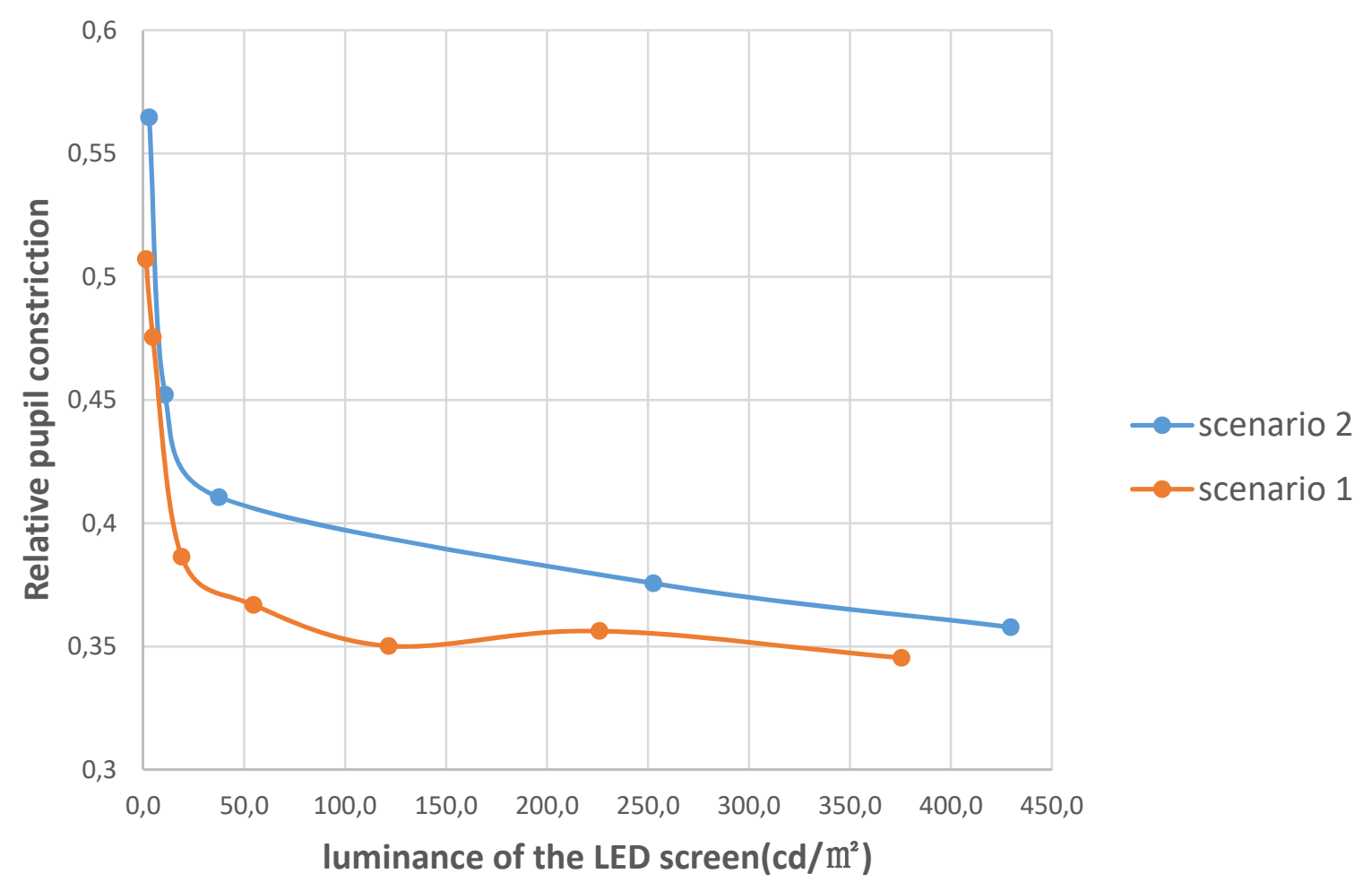

Figure 6 - Relative Pupil constriction comparison under different background luminance in the two scenarios

\subsection{Luminance distribution}

As table 2 and figure 7 shown, the pupil constriction difference among the three scenarios statistically significant, and from these data (as figure 6 shown), we can find that:

1) The same vertical illuminance on the eye do not always mean the same adaptation luminance;

2) The smaller the angle between the luminous surface and the line of sight, the higher influence power on the pupil constriction;

3) Higher uniformity of the luminance distribution can reduce the influence power on the pupil constriction.

Table 2 - Relative Pupil constriction comparison under different luminance pattern in the three scenarios

\begin{tabular}{|l|l|r|r|r|r|r|}
\hline \multirow{2}{*}{$\begin{array}{c}\text { Research } \\
\text { scenario }\end{array}$} & $\begin{array}{c}\text { Research } \\
\text { scenario }\end{array}$ & $\begin{array}{c}\text { Mean } \\
\text { difference (I-J) }\end{array}$ & $\begin{array}{c}\text { Standard } \\
\text { error }\end{array}$ & significance & \multicolumn{2}{|c|}{$\begin{array}{c}\text { 95\% } \\
\text { confidence interval }\end{array}$} \\
\hline \multirow{2}{*}{$\mathrm{sc3}$} & $\mathrm{sc4}$ & $.0623^{*}$ & .00122 & .000 & .0594 & .0652 \\
\cline { 2 - 7 } & $\mathrm{sc5}$ & $-.1186^{*}$ & .00182 & .000 & -.1229 & -.1143 \\
\hline \multirow{2}{*}{$\mathrm{sc4}$} & $\mathrm{sc3}$ & $-.0623^{*}$ & .00122 & .000 & -.0652 & -.0594 \\
\cline { 2 - 7 } & $\mathrm{sc5}$ & $-.1809^{*}$ & .00186 & .000 & -.1852 & -.1765 \\
\hline \multirow{2}{*}{$\mathrm{sc5}$} & $\mathrm{sc3}$ & $.1186^{*}$ & .00182 & .000 & .1143 & .1229 \\
\cline { 2 - 8 } & $\mathrm{sc4}$ & $.1809^{*}$ & .00186 & .000 & .1765 & .1852 \\
\hline
\end{tabular}




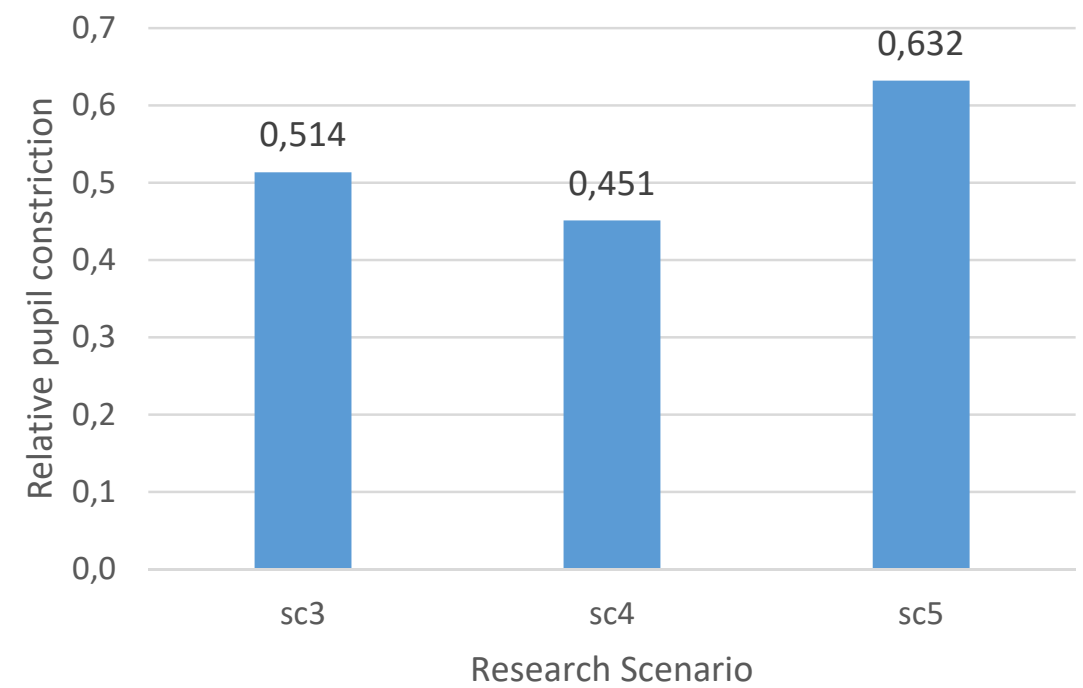

Figure 7 - Relative Pupil constriction comparison under different luminance pattern in the three scenarios

\section{Conclusion}

A preliminary research on the mathematic model of eye's adaptation luminance was conducted, from which we can found that there is some risk on evaluation the eye's adaptation by using the average luminance of the environment without considering luminance distribution. And light spectrum and luminance pattern in the environment has significant meaning on our adaptation of eyes. A further and deeper research on this topic to develop an adaptation model is needed for better understanding the mechanism of glare.

\section{Acknowledgement}

This research is founded by National Key R\&D Program of China NO. 2018YFC0705100.

\section{References}

1 CIE 2017,CIE DIS 017-2017, ILV: International Lighting Vocabulary. Vienna: CIE.

2 Rea, Mark S. ed. 2000 The IESNA Lighting Handbook Reference and Application, Ninth Edition. New York: IESNA.

3 CIE 1999. CIE 135/5:1999 VISUAL ADAPTATION TO COMPLEX LUMINANCE DISTRIBUTION. Vienna: CIE.

4 CIBSE 2002, Code for lighting, Oxford, Butterworth-Heinemann

5 CIE 1995. CIE 117:1995. Discomfort glare in interior lighting. Vienna: CIE.

6 CIE 1994. CIE 112:1994. Glare evaluation system for use within outdoor sports and area lighting. Vienna: CIE.

7 W. Kim, Y. Koga / Building and Environment 39 (2004) 1435-1442

8 Putnam, R., and Gillmore, W.F. 1957. "Discomfort glare at low adaptation levels II-Offaxis sources." Illuminating Engineering. 52(4):226.

9 Luckiesh, M., Guth, S.K. 1949. "Brightness in Visual Field at Borderline between Comfort and Discomfort." Illuminating Engineering 44 (11): 650-70. 
10 Lulla, A. B., and Bennett, C. A. 1981. "Discomfort Glare: Range Effects." Journal of the Illuminating Engineering Society 10 (2): 74-80.

11 TYUKHOVA YI, DISCOMFORT GLARE FROM SMALL, HIGH LUMINANCE LIGHT SOURCES IN OUTDOOR NIGHTTIME ENVIRONMENTS, University of Nebraska Lincoln,2015

12 ALLEN, AE et al (2014), Melanopsin-Driven Light Adaptation in Mouse Vision, Current Biology 24, 2481-2490

13 McNeill, D. S. et al (2011). Development of melanopsin-based irradiance detecting circuitry. Neural Development, 6(8). doi:10.1186/1749-8104-6-8

14 LUCAS, RJ et al (2014). Measuring and using light in the melanopsin age. Trend in Neurosciences, Vol. 37, No. 1,1-8 